\title{
Editorial V.14 N.32
}

\section{Sandra Regina Rech}

Doutora, Universidade do Estado de Santa Catarina / sandra.rech@udesc.br Orcid: 0000-0002-0062-6914/ lattes 


\section{Edição Variata — abril/2021}

A emergência de saúde global, que, infelizmente, ainda é assunto cotidiano desde o ano passado, revolucionou as nossas vidas. A partir de 2020, no espaço de algumas semanas, nossos hábitos começaram a ser radicalmente modificados. A utilização de equipamentos de proteção individual, o distanciamento social, a reorganização do trabalho e do estudo a partir de casa e a importância dos canais de comunicação digital são apenas alguns exemplos das transformações que foram incorporados ao nosso dia a dia. Essas mudanças afetaram estratégias de negócios e o consumo global, mas seus principais efeitos recaem sobre as pessoas. Esferas públicas, profissionais e pessoais entraram em choque.

E, foi nesse clima de instabilidade e preocupação, que esta Variata foi editada, o que contribuiu para a escolha da imagem da capa, que retrata como nos sentimos nesse momento: cansados, parados, sem poder de ação, incrédulos pelos números diários de mortes causadas pela doença, porém, igualmente sensibilizados pela dor e pelas dificuldades que muitos brasileiros estão enfrentando no dia a dia. Assim, esta edição inicia com três artigos de importantes pesquisadores internacionais, na esperança de que, em breve, possamos retomar nossos postos, de modo presencial, na comunidade acadêmica, e finaliza com um texto sobre o ensino do Design de Moda e seus efeitos durante a pandemia, um assunto atual, pertinente e em contínua discussão por docentes, discentes e instituições.

Abrindo esta edição, María López Vilar e Pedro A. Hellín Ortuño, da Universidad de Murcia, investigam sobre as tendências socioculturais e de consumo como uma nova perspectiva metodológica para a profissão publicitária. 
Discorrem sobre a necessidade do estabelecimento e do consenso de uma metodologia, juntamente com um conjunto de técnicas investigativas bem estruturadas, para o bom desenvolvimento de pesquisas de tendências.

Na sequência, o ensaio de Luis Mochizuki e Beatriz Antônio Araújo, da Universidade de São Paulo, objetiva discutir a importância e as repercussões do avanço tecnológico dos sensores vestíveis na qualidade de vida. Para isso, a moda, como forma de compreender como acontecem as escolhas das pessoas, pode contribuir para o desenvolvimento adequado da qualidade de vida, discutindo como equilibrar a introdução dos sensores vestíveis no dia-a-dia, as liberdades individuais, e os interesses coletivos públicos e corporativos privados.

Regina Aparecida Sanches, Adriana Yumi Sato Duarte e Maria Antonietta Sbordone, investigadoras da USP, e Patrizia Ranzo, da Università degli Studi della Campania Luigi Vanvitelli, apresentam algumas inovações tecnológicas utilizadas na fabricação de produtos de malha. Ressaltam que as inovações tecnológicas nas máquinas de malharia estão, aos poucos, tornando a moda mais sustentável, através de novas formas de produção têxtil mais eficientes, que evitam desperdício de água, energia e matéria-prima, além de eliminar a poluição.

Em seguida, no trabalho Discursos Éticos e Estéticos: uma análise semiótica de editoriais fotográficos de marcas de fast fashion e slow fashion, Letícia Formoso Assunção, Amália Kusiak Martinez e Jocelise Jacques de Jacques analisam os valores simbólicos e as estratégias discursivas presentes em editoriais de moda produzidos por dois diferentes modelos de empresas de vestuário, utilizando o aparato teóricometodológico da semiótica discursiva desenvolvida por Algirdas Julien Greimas. 
O quinto manuscrito, Cool, Absorbing, Obvious: uma perspectiva semiótica da marca Pantys, escrito por Letícia Casagrande Dai Bello, Pauliane Goularte Duarte e Murilo Scóz, também faz uso dos conceitos da semiótica greimasiana e traz uma análise do vídeo institucional presente no site da marca Pantys, com o objetivo de identificar o discurso da empresa.

No desenrolar da revista, As Alternativas de Materiais e Processos mais Sustentáveis para a Indústria Têxtil Atual são apresentadas no artigo de Ana Paula Provin, Anelise Leal Vieira Cubas e Ana Regina de Aguiar Dutra. De caráter bibliográfico, os resultados apontam para novas possibilidades de têxteis nos campos da engenharia, biotecnologia e do design.

Continuando com o assunto sustentabilidade, Kyung $\mathrm{Ha}$ Lee e Francisca Mendes questionam de que forma a sustentabilidade está sendo incorporada nos modelos de negócios presentes na moda sustentável. A partir da compreensão dos principais conceitos de moda sustentável e dos modelos de negócios existentes nos dias de hoje, as autoras fazem uso de oito arquétipos de negócios sustentáveis com o escopo de verificar quais deles são aplicáveis à indústria da moda.

Andressa Santos Turcatto e Icléia Silveira desenvolveram um estudo sobre etiquetas táteis com elementos do design de superfície para deficientes visuais, atendendo suas necessidades durante a compra e no uso diário. Através de um estudo exploratório, foram realizadas entrevistas com o público alvo na Associação Catarinense de Integração ao Cego - ACIC, como análise da interação dos deficientes visuais com o vestuário.

O Codesign para a Geração de Valor e Inovação no Desenvolvimento de Produtos de Vestuário, de Luciana da Silva Bertoso e Adriano Heemann, aborda os processos de 
inovação em empresas de vestuário, com intuito de analisar como a colaboração entre os stakeholders podem contribuir para a geração de valor e inovação. Os resultados apresentados e discutidos revelam aspectos novos sobre os fatores causais da criação de valor e da inovação.

Roteiros e Modelos para a Identificação de Tendências Socioculturais e a sua Aplicação Estratégica em Produtos e Serviços, de Nelson Pinheiro Gomes, Suzana Cohen, William Afonso Cantú e Clarissa Martins Alves Lopes, explora as interseções existentes entre a análise da cultura como processo para a identificação de mentalidades existentes, mediante um roteiro que facilite a observação/recolha e a sistematização de informação para apresentar um texto descritivo sólido das tendências. Para além disto, os autores sublinham os principais resultados da aplicação da investigação de tendências num mapa de potenciais produtos e serviços num âmbito estratégico que abordam este conhecimento.

Como penúltimo trabalho nesta edição, Luciana Borges e Vinicius Gadis Ribeiro abordam o Ensino de Moda em tempos de pandemia causada pelo COVID-19. O texto apresenta as alterações decorrentes do planejamento de atividades didáticas remotas no ensino de modelagem de vestuário em relação ao ensino presencial.

E, fechando esta edição, Débora Pires Teixeira analisa a representação da velhice na obra do estilista brasileiro Ronaldo Fraga. O trabalho constitui-se de uma reflexão teórica sobre velhice e moda, a partir de três desfiles do estilista no São Paulo Fashion Week (2009, 2017, 2018), nos quais o velho apareceu como modelo.

Finalizo esta Variata desejando uma inspiradora leitura, cruzando os dedos para que a vacina contra o coronavírus 
chegue o mais rápido possível a todos os cidadãos brasileiros e alertando, se puder, \#fiqueemcasa. 